\title{
NuRSES' AND DOCTORS' PERCEPTIONS REGARDING THE IMPLEMENTATION OF A TRIAGE SySteM IN AN EMERGENCY UNIT IN SOUTH Africa
}

\section{Authors:}

Jean E. Augustyn

Valerie J. Ehlers

Susanna P. Hattingh ${ }^{1}$

\section{Affiliations:}

${ }^{1}$ Department of Health

Studies, University of

South Africa, South Africa

\section{Correspondence to:}

Valerie J. Ehlers

e-mail:

ehlervj@unisa.ac.za

\section{Postal address:}

PO Box 65075,

Erasmusland, 0165, South Africa

\section{Keywords:}

Cape Triage Score;

emergency unit; nurse

triage; trauma nursing;

triage system

Dates:

Received: 04 Apr. 2008

Accepted: 04 May 2009

Published: 30 July 2009

How to cite this article: Augustyn, J.E., Ehlers, V.J. \& Hattingh, S.P., 2009, 'Nurses' and doctors' perceptions regarding the implementation of a triage system in an emergency unit in South Africa',

Health SA Gesondheid 14(1), Art. \#464, 8 pages. DOI: 10.4102/hsag.v14i1.464

\section{This article is available} at:

http://www.hsag.co.za
(C) 2009. The Authors. Licensee: OpenJournals Publishing. This work is licensed under the Creative Commons Attribution License.

\section{ABSTRACT}

Triage assessment of patients on arrival at an emergency unit is an essential function in quality emergency care provision, and is a cost-effective and time saving venture. This study investigated nurses' and doctors' perceptions about the implementation of the Cape Triage Score in one emergency unit. The challenges encountered prior to the implementation of the Cape Triage Score and the roles and core competencies of the triage nurse were addressed as well as the strengths and weaknesses of the Cape Triage Score. In this descriptive, quantitative and exploratory study, 15 nurses and doctors completed questionnaires. The challenges decreased and the sorting of patients improved after the implementation of the Cape Triage Score. Other strengths of this system included that the triage nurse prioritised patients, as opposed to the receptionist or the administrative staff; and nurses could undertake preliminary investigations without waiting for doctors' orders to do so. The weaknesses of the implemented Cape Triage Score included that it was not fully functional $100 \%$ of the time, and that it was difficult to maintain during peak admission periods due to a shortage of nurses. The recommendations included that management should be convinced of the system's benefits; nurses should perform the triage function on a rotation basis; more nurses should be available during peak periods; and that the administrative and reception staff should also be orientated about the triage system.

\section{OPSOMMING}

Triage assessering van pasiënte met hulle aankoms by ' $n$ ongeluk/noodeenheid is ' $n$ noodsaaklike funksie van noodsorgvoorsiening, en is ' $n$ koste-effektiewe en tydbesparende onderneming. Hierdie studie het die persepsies van dokters en verpleegkundiges ondersoek betreffende die implementering van die Cape Triage Score in een noodeenheid. Die uitdagings wat ervaar is voor die implementering van die Cape Triage Score, die rolle en kernvaardighede van die triage verpleegkundige asook die swak en sterk punte van die Cape Triage Score is aangespreek. In hierdie beskrywende, kwantitatiewe en verkennende studie het 15 verpleegkundiges en dokters vraelyste voltooi. Uitdagings het verminder en die prioritisering van die pasiënte het verbeter na die implementering van die Cape Triage Score. Ander sterk punte van die stelsel het ingesluit dat die triage verpleegkundige die pasiënte geprioritiseer het, nie die ontvangsdame of die administratiewe personeel nie, en verpleegkundiges kon voorlopige ondersoeke doen sonder om op doktersbevele te wag. Die swakhede van die geïmplementeerde Cape Triage Score het ingesluit dat dit nog nie ten volle $100 \%$ van die tyd gefunksioneer het nie, en dat dit moeilik was om triage gedurende spitstye te handhaaf as gevolg van 'n tekort aan verpleegkundiges. Die aanbevelings het ingesluit dat bestuur oortuig moet word van die voordele van die stelsel, verpleegkundiges triage funksies op ' $n$ rotasiebasis moet uitvoer, meer verpleegkundiges beskikbaar moet wees gedurende spitstye; en dat administratiewe en ontvangspersoneel ook georiënteer moet word ten opsigte van die triage stelsel.

\section{INTRODUCTION}

Triage is described as '... putting the patient in the right place at the right time to receive the right level of care ... the allocation of appropriate resources to meet the patient's medical needs' (Bracken 2003:75). Triage is the process of sorting and prioritising patients according to their level of acuity to determine which individuals need specialised care for either actual or potential injuries or complications. If this is done successfully each patient can be directed to the most appropriate facility, specialist or unit with the least possible delay. Rendering the most appropriate type of care within the shortest time possible is one of the most important aspects in the prevention of death and disability in any emergency unit (Alarcon, Fernancez \& Wuerz 1998:432; Bekerman et al. 2001:113).

Authors such as Jones (1993:14), Mallet and Woolwich (1990:1444-1445) and Woolwich (2000:476) emphasise the following positive aspects with regard to the triaging of patients on their arrival at an emergency unit:

- The unknown factor of the illnesses and injuries of patients in the waiting room can be assessed immediately

- Overcrowding in the waiting room area can be prevented and/or managed

- The flow of patients through the emergency unit and wastage of time can be controlled

- Deterioration of already severely ill/injured persons can be assessed and managed

- Long waiting times without being seen by any health professional can be prevented as every patient is given immediate attention

- Patient dissatisfaction (and possible aggression) can be limited

- Infection control, such as blood spills and patients with infectious diseases can be managed to prevent infecting others in the waiting room

- Unsafe clinical environments (physical and psychological) for patients requiring additional assistance from professional staff are limited. 
Unbalanced workloads for nurses may also be prevented by reducing dissatisfaction and demotivation in emergency units (Swansberg 1993:292) with the effective implementation of a triage system.

The World Health Organization (WHO) (WHO 2003:16) identifies three basic rights of the injured patient on arrival at an emergency unit, namely:

- the likelihood of survival is maximised

- life threatening injuries are managed appropriately and timeously, according to priorities

- $\quad$ potentially disabling injuries are treated immediately so as to minimise functional impairment, pain and psychological suffering.

In the United States of America (USA), the United Kingdom (UK) and in the United Arab Emirates (UAE), specialist nurses perform triage functions (Pillay 2005:26). In South Africa, triage decisions might be made by pre-hospital emergency personnel based on their knowledge of the type and severity of the accident or injury (Nicol \& Steyn 2004:224). In some cases non-medical personnel, such as the admission clerks (Woolwich 2000:477) might perform triage functions by deciding which patients need immediate attention and which patients can wait to be seen at a later stage.

\section{The Cape Triage Score}

The Cape Triage Group, led by Dr Clive Balfour and Dr Lee Wallis, designed and implemented a triage system (known as the Cape Triage Score) in a number of emergency departments in the Western Cape Province (Augustyn 2006:8). This system is suitable for both in- and pre-hospital emergency use, and also for both public and private hospitals (De Vries et al. 2005:38)

The Cape Triage Score (algorithm or assessment tool) uses the following colour codes:

- $\quad$ Red: resuscitation; physiologically unstable.

- Orange: serious cases with potentially unstable physiology or potentially life/limb threatening pathology.

- Yellow: physiologically stable cases with reasonably serious medical or trauma problems.

- Green: minor injuries/illnesses.

- $\quad$ Blue: persons who have died (De Vries et al. 2005:39).

These colour classifications correspond with those used throughout South Africa, except that 'orange' has been added to distinguish between 'stable red' and 'unstable yellow' (De Vries et al. 2005:39). The Cape Triage Score adapted the Triage Early Warning System (TEWS) by matching the vital signs to scores specified in the TEWS table; adding these scores to determine the total TEWS; transferring the total scores to the symptom list of the Cape Triage Score and assigning the relevant colour code to the patient. If any aspect of the patient's history, or any signs or symptoms fall into a higher colour code category, this higher colour code is then assigned to the patient, implying that triage can only be upgraded, never downgraded during this process.

The major criticisms against any triage process include that triage is more appropriate in guiding decisions about treatment and predicting mortality in groups of patients after mass accidents, rather than for individual patients in an emergency unit. Triaging of patients could be biased towards medical patients, whose vital signs might deteriorate rapidly, at the expense of trauma patients whose vital signs might remain within normal ranges for limited periods of time even after major traumatic injuries (De Vries et al. 2005:4)

Despite theselimitations, the Cape Triage Score was implemented at the participating emergency unit in an effort to enhance the unit's operation.

\section{RESEARCH SITE}

The research site was a private hospital emergency unit providing care for minor and major trauma, accident, forensic, paediatric, surgical and medical emergencies. This unit also provided wound care, intravenous antibiotics and tended to persons with minor complaints (such as colds) on a daily basis. More than 2000 patients are seen every month. No formal triage system was in place. Most patients were seen in their order of arrival at the unit, unless an admission clerk called a nurse to tend to a specific patient.

\section{PROBLEM STATEMENT}

The problem was to determine whether the implementation of the Cape Triage Score in the emergency unit enhanced the unit's operation, according to the perceptions of the doctors and nurses working in this unit.

\section{Purpose and objectives of the study}

The purpose of this research was to identify doctors' and nurses' perceptions about the implementation of the Cape Triage Sore. The research objectives of this study attempted to:

- identify challenges encountered in the emergency unit prior to the implementation of the Cape Triage Score

- describe the role of the nurse in the triage of patients

- determine the core competencies of the nurse in the triage of patients

- identify strengths of the newly implemented Cape Triage Score

- identify weaknesses of the newly implemented triage system

- make recommendations for the further improvement of the newly implemented triage system.

\section{Significance of this research}

The results of this study could help to improve the operations of the emergency unit, and could provide guidelines for other emergency units concerning the implementation of a triage system.

\section{Definitions of key concepts}

For the purpose of this research, 'emergency' means any physical, psychological or medical condition admitted to the emergency unit. The emergency unit refers to a well equipped level II accident and emergency facility of a private hospital with a two-bed resuscitation room with overhead gantry x-rays one-bed isolation room; two-bed overnight room; one general emergency room area with eight beds/patient cubicles; triage room (used for wound care at the onset of the research in 2005); two doctors' consultation rooms and a reception/waiting area with 34 chairs.

A 'private hospital' is defined by the Department of Health (South Africa, 2003: Section 1) as 'a health establishment that is not owned nor controlled by the state.'

'Prioritisation of patients' in this study refers to the order in which patients in the waiting room are attended to. This ranking is influenced by the severity of each patient's condition and/or injuries.

'Triage' is derived from the French word 'trier' which means to 'pick or to sort'. Patients or problems are thus sorted according to their degree of seriousness - their need for treatment - and the available resources to offer the treatment (American College of Surgeons Committee on Trauma 1997:25; Bracken 2003:75; Caroline 1995:438). In this research, 'triage' is the prioritising (by an assigned nurse or doctor) of patients who arrive at the participating emergency unit. 
'Quality of care' is 'the degree to which health services for individuals and populations increase the likelihood of desired health outcomes and are consistent with current professional knowledge' (Lohr 1990:21). In this research, quality care refers to the service of excellence by triaging, provided to patients admitted to a specific emergency unit.

\section{RESEARCH DESIGN AND METHODS}

An exploratory, quantitative and descriptive design was used in this research. Factual (quantitative) information was desired to identify whether the implementation of the Cape Triage Score in the emergency unit produced any positive results according to the doctors and nurses working in this unit. The questionnaires were completed anonymously, implying that confidentiality was maintained as nobody, not even the researchers, knew which respondent provided what information.

\section{Target population}

A target population is a population of 'interest to the proposed investigation' (Saks \& Allsop 2007:157). In this study, the population consisted of all nurses and doctors involved in receiving patients in the emergency unit. In this study, 15 participants met the inclusion criteria of working in the emergency unit as a nurse or medical doctor assigned to prioritise patients admitted to the emergency unit.

\section{Research instrument}

Research objectives in a quantitative study must be accomplished by the data collected (Burns \& Grove 2001:50). The questionnaire was structured according to the study problem, purpose and objectives. In this study, questionnaires with closed-ended questions were used to collect information from participants working in the selected emergency unit. One open-ended question requested respondents' opinions about any aspect not addressed in the questionnaire. As all participants could communicate in English, and as all were familiar with the English emergency care terminology, there was no need to translate the instrument. The questionnaire comprised the following sections: demographic information, challenges experienced before the implementation of the Cape Triage Score, perceptions of the triage nurse's role and core competencies, strengths and weaknesses of implementing the Cape Triage Score, and recommendations for improving the triage system.

In the demographic section questions were asked about the respondents' gender, age, professional status, years of experience and training in emergency medicine/nursing, previous triage experience, and type of triage used. Questions asked about the challenges experienced prior to the implementation of the Cape Triage Score included items about patients' waiting times, staff members who actually performed the prioritising of patients, investigations conducted by nurses, patient flow and the safety of the environment incorporating aspects of infection control. In the section on nurses' roles during triage, specific items addressed nurses' prioritising of patients, instituting of first aid measures, conducting physical examinations and other investigations, keeping the patients and their relatives informed and controlling the waiting room area. The section on the core competencies of triage nurses included items about interpersonal and communication skills with patients and family members, maintaining patients' vital signs and performing basic life support processes, and specific functions such as taking and reading an electro cardiogram (ECG). The strengths and weaknesses of implementing the Cape Triage Score were measured by asking respondents to rate the acceptability and manageability of specific aspects of the triage system before and after implementation of this system. Suggestions about any aspect not addressed in the questionnaire were requested in an open-ended question. According to LoBiondo-Wood and Haber (1998:316), 'open-ended items are used when the researcher wants the subjects to respond in their own words or when the researcher does not have all of the possible alternative responses.' By including this open-ended item, aspects not covered in the closed-ended items could be identified by the respondents.

Two nurse researchers, three nurses working in trauma units, and an expert nurse educator, teaching trauma courses, evaluated the questionnaire items and agreed that every item addressed a specific aspect relevant to the implementation of the Cape Triage Score at one emergency unit. No pre-testing of the questionnaire was done as the entire population of nurses and doctors involved with the actual implementation of the Cape Triage Score participated in the study.

\section{Validity and reliability}

Polit, Beck and Hungler (2001:308) define reliability as 'the consistency with which an instrument measures an attribute.' Burns and Grove (2001:399) add that for an instrument to be reliable it must yield the same measure when used on more than one occasion. Testing the questionnaire on more than one occasion was impossible during the current study because the responses of the target population of nurses and doctors (who worked in the participating emergency unit) responses required in the exploratory descriptive study.

Another attribute of an instrument related to reliability is the internal consistency or homogeneity with which the items within the scale reflect or measure the same concept. This means that the items within the scale correlate or are complementary to each other.

(LoBiondo-Wood \& Haber 1998:341)

During the development phase of the instrument, only items necessary to achieve the research objectives were included. Literature sources were consulted and critique was obtained from three nurses working in the field of triaging, from two nurse researchers and from one nurse educator teaching post basic trauma nursing courses, to ensure that every item was relevant to triage in an emergency unit. The six critical evaluators of the questionnaire's items agreed that every item measured an aspect relevant to triage in an emergency unit. No statistical tests were conducted to determine the reliability of the instrument's items.

Polit et al. (2001:308) define validity as 'the degree to which an instrument measures what it is supposed to measure.' Six nurse evaluators agreed that the questionnaire items appeared to be measuring only aspects relevant to triage in an emergency unit, thus accepting its face validity (LoBiondo-Wood \& Haber 1998:332). These six nurse experts rated the relevance (to triage) of every item to be at least 4 (out of a possible 5). Thus only items with a content validity index (CVI) of at least 0.80 were retained in the questionnaire. Items with lower scores were discarded or rephrased and resubmitted to the six evaluators until the CVI reached 0.80 .

\section{Data collection procedure}

Each participant was handed a questionnaire during a specific morning. The anonymously completed questionnaire (sealed in a blank envelope) was collected at a predetermined time during the same day, and vice versa for persons who were working night duty shifts. Persons who were on leave were also contacted and completed their questionnaires at predetermined mutually acceptable times and places. All the distributed questionnaires were completed and returned. Every respondent was requested to complete the questionnaire anonymously and confidentially, not to discuss the questionnaire items with colleagues, and to complete the questionnaire as soon as possible. The administrative personnel were instructed not to complete any questionnaire, as these were meant to be completed by doctors and nurses only. One researcher was present in the emergency unit during the day and the night when the questionnaires were completed, in order to answer any queries. 


\section{Data analysis}

The Excel (Microsoft Office version 2003) computer program was used to analyse the data, with the assistance of a statistician. The answers to the open-ended questions (requesting suggestions about any aspects not addressed in the questionnaire) were grouped and the responses in each group were counted and presented as such. Frequencies and percentages were calculated and presented in tables and graphs.

\section{ETHICAL CONSIDERATIONS}

Permission was obtained from the manager of the private hospital and from the Research and Ethics Committee of the Department of Health Studies at the University of South Africa.

Burns and Grove (2001:206) state informed consent consists of four elements, namely disclosure of essential information, comprehension, competence and voluntarism. A research information brochure and a letter were attached to each questionnaire. Respondents were thus fully informed about the nature and scope of the research project, and as they were working in an emergency unit, it was assumed that they comprehended the contents of this brochure and were competent to complete the questionnaires. Voluntarism was attained because participants were under no obligation to complete the questionnaires and would not suffer any negative consequences for refusing to do so. No remuneration was paid. In order to maintain anonymity and confidentiality no signed consent form was included. Completing and returning the questionnaire was accepted as implied consent.

The completed questionnaires were kept locked up. Only the researchers and the statistician had access to the raw data. The data entered into a computer were linked to a secret password and were only accessible to the researchers and the statistician. After the acceptance of the research report, the completed questionnaires were shredded and the data on the computer were deleted.

\section{RESULTS}

The findings obtained from the 15 completed questionnaires will be presented in this section while the results will be discussed in a separate section of this article. Demographic data about the 15 respondents will be provided initially so that the rest of the data can be contextualised against this background information.

\section{Demographic data}

Most respondents were females $(80.0 \% ; \mathrm{n}=12)$ and 30 years of age or older $(93.3 \%$; $n=14)$. Of the respondents $80.0 \% \quad(n=12)$ were nurses (of whom only two had completed their trauma training) and the remainder $(20.0 \%$; $n=3)$ were emergency unit doctors. All respondents had more than two years' experience in an emergency unit with $60.0 \%(\mathrm{n}=9)$ having had more than 10 years' experience in this field.

Of the respondents, $33.3 \%(\mathrm{n}=5)$ practised intermediate triage, $26.7 \%(n=4)$ had never practised triage, $26.7 \%(n=4)$ practised non-professional triage and $13.3 \%(n=2)$ practised basic triage. Only one person had experienced advanced triage, while $13.3 \%$ $(\mathrm{n}=2)$ indicated that they had conducted triage in the pre-hospital environment. Nobody had any experience of telephone triage.

\section{Challenges encountered in the unit prior to the implementation of the Cape Triage Score}

The most prominent challenges prior to the implementation of the Cape Triage Score were the patients' complaints about their long waiting times $(86.6 \% ; \mathrm{n}=13)$ and the time taken for doctors to see patients $(80.0 \% ; n=12)$. In addition, $53.3 \%(n=8)$ of the respondents indicated that receptionists and administrative staff incorrectly prioritised patients. As many as $53.3 \%(n=8)$ of the respondents indicated that nurses had to wait for doctors' written orders before minor investigations could be conducted, necessitating a doctor to see a patient twice $(40.0 \%$; $n=6)$, contributing to the patients' lengthy waiting times. Limited investigations could have been performed by a nurse prior to the patient being seen by a doctor, according to $40.0 \%(n=6)$ of the respondents. Patients' dissatisfaction and aggression were attributed to long waiting times by $46.6 \%(n=7)$ of the respondents while $46.6 \%(n=7)$ also indicated that nurses and doctors did not always know what illnesses or injuries were in the waiting room. Only a minority of respondents regarded the following aspects as challenges: lack of patient flow through the unit, patients were not necessarily attended to according to the seriousness of their conditions, serious patients should be assessed/referred faster, nurses' unbalanced workloads, unsafe

TABLE 1

Challenges experienced before triage had been implemented

\begin{tabular}{|c|c|c|}
\hline PROBLEMS EXPERIENCED & $\begin{array}{l}\text { RESPONDENTS } \\
\quad \mathrm{N}=15\end{array}$ & PERCENTAGE \\
\hline Patients complained that they waited too long & 13 & $86.6 \%$ \\
\hline Long waiting times to see the doctor & 12 & $80.0 \%$ \\
\hline Incorrect decision-making by reception and administrative staff of who should sit and wait and who should be assisted by a nurse & 8 & $53.3 \%$ \\
\hline $\begin{array}{l}\text { Nurses wait for the doctor, when they already know what procedures / investigations will follow, subsequently increasing waiting time } \\
\text { and inadvertently waste even more time }\end{array}$ & 8 & $53.3 \%$ \\
\hline Nursing and medical staff did not know what patients' illnesses and injuries were in the waiting room & 7 & $46.6 \%$ \\
\hline Patient dissatisfaction and aggression & 7 & $46.6 \%$ \\
\hline $\begin{array}{l}\text { Patients needed to be seen by the doctor twice whereas small investigations may have already been undertaken prior to their being } \\
\text { seen by the doctor }\end{array}$ & 6 & $40.0 \%$ \\
\hline Lack of flow of patients through the department and wastage of time & 5 & $33.3 \%$ \\
\hline Patients were not necessarily rapidly attended to by the doctor in terms of the seriousness of their problems & 5 & $33.3 \%$ \\
\hline $\begin{array}{l}\text { Time is wasted where more serious patients could be assessed by the doctor and then be investigated and/or referred to a specialist } \\
\text { more timeously }\end{array}$ & 5 & $33.3 \%$ \\
\hline Overcrowding in the waiting room & 4 & $26.6 \%$ \\
\hline Unbalanced workloads for nurses & 2 & $13.3 \%$ \\
\hline Unsafe clinical environments for patients requiring additional assistance such as distressed/psychiatric patients & 2 & $13.3 \%$ \\
\hline Deterioration of already severely ill/injured patients & 1 & $6.7 \%$ \\
\hline Poor infection control, such as blood spills or patients with infectious diseases infecting others whilst waiting in the waiting room & 1 & $6.7 \%$ \\
\hline No problems were experienced & 0 & $0 \%$ \\
\hline
\end{tabular}


TABLE 2

The nurses' role during triage

\begin{tabular}{|c|c|c|}
\hline THE NURSES' ROLE DURING TRIAGE & $\begin{array}{l}\text { RESPONDENTS } \\
\mathrm{N}=15\end{array}$ & PERCENTAGE \\
\hline Prioritisation of patients & 13 & $86.7 \%$ \\
\hline Institute first aid measures where necessary & 12 & $80.0 \%$ \\
\hline Brief investigations such as urinalysis, pregnancy test and haemogluco test & 11 & $73.3 \%$ \\
\hline Keep patients and relatives informed of delays, expected time to be seen & 11 & $73.3 \%$ \\
\hline Manage the waiting room, controlling overcrowding and getting a brief overview of each patient's problem & 10 & $66.7 \%$ \\
\hline Crisis intervention and ensuring patients' safety, assisting very distressed patients or relatives/friends & 10 & $66.7 \%$ \\
\hline Focused physical examination and taking of vital signs & 10 & $66.7 \%$ \\
\hline $\begin{array}{l}\text { The nurse must be at the frontline of the unit, together with the reception/administrative staff, to alleviate non-medical staff's decision- } \\
\text { making of who should be seen first and who is well enough to have his/her hospital file opened }\end{array}$ & 9 & $60.0 \%$ \\
\hline Assessment of patient & 8 & $53.3 \%$ \\
\hline Patient/client relations, thereby improving patients' satisfaction & 8 & $53.3 \%$ \\
\hline Infection control, for example preventing blood spills and referring patients with a potential infectious disease to an isolated area & 8 & $53.3 \%$ \\
\hline Initiate contact with patients and family & 7 & $46.6 \%$ \\
\hline Manage patient flow through the unit, knowing where patients are on arrival & 7 & $46.6 \%$ \\
\hline Documentation & 7 & $46.6 \%$ \\
\hline Allocate patients appropriately to a specific nurse or doctor, evenly distributing workloads amongst staff & 6 & $40.0 \%$ \\
\hline Reduce nurses' stress/tension levels & 6 & $40.0 \%$ \\
\hline Reduce the emergency doctors' stress/tension levels & 5 & $33.3 \%$ \\
\hline Inform the unit manager or senior nurse of unusual problems or occurrences & 5 & $33.3 \%$ \\
\hline Control Overcrowding in the waiting room & 4 & $26.6 \%$ \\
\hline Gauge potential admissions to hospital & 3 & $20.0 \%$ \\
\hline Function independently and direct others in stressful situations & 3 & $20.0 \%$ \\
\hline Reduce reception/administrative staff's stress/tension levels & 2 & $13.3 \%$ \\
\hline Other: Cope with any physical or other problems that may arise & 1 & $6.7 \%$ \\
\hline
\end{tabular}

TABLE 3

Core competencies required by the nurse during the triage of patients

\begin{tabular}{|c|c|c|}
\hline CORE COMPETENCIES REQUIRED BY THE NURSE DURING TRIAGE OF PATIENTS & $\begin{array}{l}\text { RESPONDENTS } \\
\mathrm{N}=15\end{array}$ & PERCENTAGE \\
\hline Good interpersonal skills: crisis intervention: distressed patients and relatives & 13 & $86.7 \%$ \\
\hline Primary assessment (ABC: airway, breathing, circulation) & 13 & $86.7 \%$ \\
\hline Take vital signs & 12 & $80.0 \%$ \\
\hline Determine level of consciousness & 11 & $73.3 \%$ \\
\hline Basic life support procedures (such as basic CPR: cardio-pulmonary resuscitation) & 11 & $73.3 \%$ \\
\hline Basic life support procedures (such as basic CPR) & 11 & $73.3 \%$ \\
\hline Perform an ECG (electro-cardiogram) & 10 & $66.7 \%$ \\
\hline Taking and documenting medical history & 10 & $66.7 \%$ \\
\hline Perform a urinalysis & 10 & $66.7 \%$ \\
\hline Perform a blood glucose measurement & 9 & $60.0 \%$ \\
\hline Specific assessment: healing of sutured wound prior to removal of sutures & 8 & $53.3 \%$ \\
\hline Perform a blood haemoglobin measurement & 8 & $53.3 \%$ \\
\hline Utilise pulse oximetry & 8 & $53.3 \%$ \\
\hline Specific assessment: Plaster of Paris check & 7 & $46.7 \%$ \\
\hline Removal of sutures & 7 & $46.7 \%$ \\
\hline Interpret an ECG & 6 & $40.0 \%$ \\
\hline Secondary assessment (head-to-toe) & 3 & $20.0 \%$ \\
\hline Manage medico-legal aspects & 3 & $20.0 \%$ \\
\hline Advanced life support procedures (such as defibrillation, administration of adrenaline) & 2 & $13.3 \%$ \\
\hline
\end{tabular}

clinical environment and poor infection control. No respondent reported that no problems/challenges were encountered in the unit.

\section{Respondents' perceptions about nurses' roles during triage}

The most important nurses' roles during triage, according to respondents, are to prioritise patients $(86.7 \%$; $n=13)$; institute first aid measures $(80.0 \%$; $n=12)$; conduct investigations such as urinalysis, pregnancy tests and blood glucose levels (73.3\%; $\mathrm{n}=11$ ); keep the patients and relatives informed about delays and the expected times to be seen by the doctor $(73.3 \%$; $n=11)$; ensure patients' safety, assisting distressed patients and their families and performing physical examinations $(66.7 \%$; $n=10)$; control the waiting room area by preventing overcrowding and obtaining a brief history from each patient $(66.7 \% ; \mathrm{n}=10)$; and to improve patient/client relations (53.3\%; $\mathrm{n}=8$ ). 
Interacting with patients/clients and overseeing documentation, reducing other nurses', doctors' and administrative staff members' stress levels, managing the flow of patients through the unit, informing the unit manager about unusual problems or occurrences, gauging potential admissions to the hospital and predicting any physical or other problems were regarded as the nurses' roles by a minority of respondents.

\section{Respondents' perceptions about nurses' triage core competencies}

As many of $86.7 \% \quad(n=13)$ of the respondents regarded good interpersonal skills during crisis intervention and the management of distressed patients and their relatives, as well as the primary assessment of the patient $(86.7 \% ; n=13)$ and the monitoring of the patient's vital signs $(80.0 \% ; n=12)$ as the most important triage core competencies of the nurse. Of the respondents, $73.3 \%(n=11)$ indicated that the determination of the level of consciousness of the patient as well as the ability to perform basic life support procedures $(73.3 \%$; $n=11)$ are vital core competencies.

Two-thirds of the respondents $(66.7 \% ; n=10)$ agreed that other core competencies included performing electro-cardiograms, accurately documenting medical histories and performing urinalysis while $60.0 \%(\mathrm{n}=9)$ considered performing a blood glucose determination to be a core function. Other actions that were regarded by $53.8 \% \quad(n=8)$ of the respondents as core functions were the assessment of wound healing prior to removing sutures, performing haemoglobin tests and utilising pulse oximetry results.

The respondents did not agree 100\% about nurses' core competencies required during triage.

\section{Respondents' perceptions about the implementation of the Cape Triage Score}

Triage was reported to be 'good' by $13.3 \% \quad(n=2)$ of the respondents prior to the Cape Triage Score implementation versus a $40.0 \%(n=6)$ rating after this implementation. The 'acceptable' rating improved from $40.0 \%(n=6)$ to $53.3 \%(n=8)$ after the implementation of the Cape Triage Score.

\section{Strengths of implementing the Cape Triage Score}

Subsequent to the implementation of the Cape Triage Score almost all $(93.3 \%$; $=14)$ respondents felt satisfied and empowered; none felt they had been inadequately trained or that triage fell beyond their scope of practice. An overall positive attitude was reported by the respondents who felt that their morale had improved $(6.7 \% ; n=1)$, that they felt more responsible $(40.0 \% ; n=6)$ and that the unit was running more smoothly $(20.0 \% ; n=3)$ as well as maintaining better control $(26.7 \% ; n=4)$.

Almost all respondents $(93.3 \% ; n=14)$ indicated that the institution of first aid measures was necessary in the triage area. Of the respondents, $86.6 \%(n=13)$ indicated that the Cape Triage Score is scientifically calculated, that prioritisation of patients is done, crisis interventions are conducted thereby enhancing patients' safety, assisting very distressed patients or relatives/ friends more effectively, and that the relationships of patients/ relatives/friends with nurses had improved.

As many as $80.0 \%(n=12)$ of respondents indicated that the Cape Triage Score was easy to manage. Of the respondents, $73.3 \%$ $(n=11)$ stated that the Cape Triage Score was objective, the unit's layout was conducive to triage and more effective infection control was implemented. In addition, $73.3 \%(n=11)$ regarded the implementation of the Cape Triage Score as allowing nurses to act independently empowering them to direct others during stressful situations.

Of the respondents, $66.7 \%(n=10)$ indicated that the new triage score initiated more contact with patients and family members and that brief investigations such as urinalysis, pregnancy tests and haemogluco tests could be carried out without delays caused by waiting for the doctors' orders for these tests.

Of the respondents, $66.7 \%(n=10)$ regarded the new Cape Triage Score as a strength regarding the reduction in the stress levels of nurses, doctors and administrative staff. In addition, 53.3\% $(n=8)$ indicated that relatives and patients were informed about delays, more focused physical examinations were conducted and documented and patients' vital signs were taken on arrival.

Only $40.0 \%(n=6)$ of the respondents regarded the management of the waiting room, controlling of overcrowding and a brief overview of each patient's problem and the assessment (history taking) of the patient on arrival as being a strength of the Cape Triage Score. Only $26.7 \%(n=4)$ of the respondents regarded the gauging of potential admissions to the hospital to be a strength.

\section{Weaknesses of implementing the Cape Triage Score}

Two major weaknesses were that $66.7 \%(n=10)$ of the respondents regarded the system as not fully functioning $100 \%$ of the time and $46.7 \%(n=7)$ indicated that potential admissions were not gauged and that history taking of patients was not always conducted on arrival. Other negative responses indicated that the process of triage was not yet flowing smoothly $(20.0 \% ; n=3)$, and that some respondents were still inexperienced $(6.7 \% ; n=1)$ in performing triage functions.

\section{Respondents' recommendations for enhancing the newly implemented triage system}

As many as $80.0 \%(n=12)$ of the respondents indicated that more nurses were needed to have the system functioning effectively $100 \%$ of the time. In addition, $53.3 \%(n=8)$ indicated that hospital management should buy into the system, and $33.3 \% \quad(n=5)$ indicated that communication should improve between doctors and nurses. Other recommendations made by $26.7 \%(n=4)$ of the respondents included that triage should be conducted in the reception area, one designated nurse should do triage and that nurses should rotate on a daily basis in the triage area.

Three $(20.0 \%)$ respondents indicated that they needed more practice and supervision in conducting triage. Two (13.3\%) respondents suggested ongoing training as the system develops and that experiences should be addressed during training sessions.

As many as $33.3 \%(n=5)$ of the respondents stated that the triage room was not adequately equipped and that dipstix haemoglucose tests and other equipment were not always readily available. They also suggested that one designated person should be allocated to the triage area and that administrative staff should receive basic training in triage. One respondent suggested that triage should only be performed when there are more than four patients in the waiting area.

\section{DISCUSSION}

The most important challenges encountered prior to the implementation of the Cape Triage Score concerned patients' long waiting times. The most important roles of the nurse during triage were reportedly the prioritisation of patients and the institution of first aid measures, followed by communication with patients and relatives as well as conducting minor investigations. However, the most important core competencies of the nurse were perceived to be doing primary assessments and maintaining good interpersonal relations with patients and relatives while implementing crisis interventions.

Nielson (2004:336) and Woolwich (2000:476) report that effective nurse-patient/family relationships and communication reduce anxiety and enhance patients' levels of satisfaction with the care rendered. The implementation of the Cape Triage Score 
apparently facilitated the prioritisation of patients as most respondents felt empowered thereby. Similar findings have been reported by Heyns (2002:77) and by Almes et al. (2004:263).

The only other challenges encountered prior to the implementation of the Cape Triage Score that obtained more than $50 \%$ of the responses were that the administrative staff incorrectly prioritised patients and that nurses had to wait for doctors' written orders before conducting minor investigations. Both these challenges were addressed by the implementation of the Cape Triage Score. Other researchers also reported that triage done by nurses enhanced the prioritisation of patients (Edwards 1999:20; Gottschalk 2004:326; Parish 2000:6).

The respondents did not agree $100 \%$ about the core competencies expected of nurses during the triage of patients. However, $73.3 \%$ $(n=11)$ or more agreed that such core competencies included: maintaining good interpersonal relationships with clients and family members, doing primary assessments, taking vital signs, and instituting basic life support procedures. These identified core competencies are not included in Bucknall and Gerdtz's (2000:28) list of nurses' triage tasks, but might be specific to the unit participating in this study.

Although most respondents perceived the effects of the implementation of the Cape Triage Score positively, some reported that it could not be maintained $100 \%$ of the time because there were too few nurses to do so. Woolwich (2000:478) reports that investing in a triage system is a costly exercise requiring up to $15.0 \%$ of the nursing budget. This author further warns that triage can only be successful if the triage nurse can assign the rendering of immediate first aid measures (such as cardiac resuscitation or arresting haemorrhage) to another caregiver while $\mathrm{s} /$ he resumes the triaging of patients.

\section{LIMITATIONS OF THE STUDY}

The study's findings are limited to one participating emergency unit in a private hospital. The findings cannot be generalised to other private hospitals' emergency units nor to those of public hospitals. Only 15 respondents participated in this study, further limiting the generalisability of the results. The study utilised only self-completion questionnaires to gather data. Triangulation of research instruments might have added other dimensions to the data. In-depth individual and/or focus group interviews, yielding qualitative data, could have enriched the quantitative data obtained from the completed questionnaires.

Questionnaires were only handed out after the implementation of the Cape Triage Score, not prior to its implementation. No observations were recorded about patients' waiting times nor about the prioritisation of patients prior to and subsequent to the implementation of the Cape Triage Score.

\section{RECOMMENDATIONS}

The findings of this study could serve as guidelines for research prior to the future implementation of the same or similar triage systems in other emergency units.

Nurses should be trained specifically to perform triage functions and should perform these functions on a rotating basis. Regular in-service education sessions should evaluate the successes and failures of triage experiences during the preceding weeks. Triage challenges should be identified, researched and addressed.

Regular triage nurses should be able to initiate preliminary tests without waiting for the doctors' prescriptions to save time, according to policies accepted by the hospital's managers.

The need for additional nurses during peak periods should be investigated, quantified and addressed in the most cost-effective manner possible. For example, specific nurses and doctors could be 'on-call' from 16:00 until 24:00, to assist if the workflow increases beyond the capacity of the available nurses and doctors during peak hours.
Shortages of equipment should be listed on a daily basis so that the situation can be remedied.

Regular assessments should be done of the time that patients have to wait before being attended to in the emergency unit.

Monthly audits should be done on these waiting times, and about equipment shortages, and all the personnel of the emergency unit should be informed about these results. Hospital management should be informed about these monthly audits and about the positive contributions of the triage system towards enhancing patient care, as well as challenges encountered.

The financial cost of maintaining a triage system, such as the need for an additional registered nurse, should be quantified and weighed against aspects of improved patient care, such as reduced waiting times, increased patient security, reduced morbidity and mortality figures, and increased levels of staff members' job satisfaction.

Nurses and doctors should be encouraged to attend training sessions in implementing the Cape Triage Score and to visit other hospitals where this system has been implemented. Staff members could each visit a different centre and provide feedback to the entire group of doctors and nurses working in this unit. Based on the identified strengths and weaknesses of the visited centres, best practice guidelines for this unit should be compiled and tested.

Nurses performing triage functions should be requested to keep a diary of challenges encountered and suggestions for addressing these challenges in future. Regular focus group discussions about nurses' triage experiences should be conducted. In this way, the Cape Triage Score could be adapted to the unique needs of this specific unit, possibly saving time and money.

Receptionists and administrative staff members should also be orientated about the triage process. Future studies should conduct two investigations, before and after the implementation of the Cape Triage Score, in a specific unit. This will produce comparative data and enable the calculation of correlation statistics.

\section{CONCLUSION}

After the implementation of the Cape Triage Score, the ratings increased to over $90 \%$ judging the newly implemented triage system to be acceptable or good. Respondents generally perceived the newly implemented triage system as being positive, enhancing the operations of the unit. Problems related to operational failures that could improve over time, including inexperience, the triage process' initial implementation problems and the shortages of equipment and nurses. Regular audits and in-service education could address these challenges successfully.

\section{REFERENCES}

Alarcon, J., Fernandez, C.M.B. \& Wuerz, R., 1998,'Inconsistency in emergency department triage', Annals of Emergency Medicine 32(4), 431-435.

Almes, E., Davis, B.A., Elder, R. \& Littlepage, N., 2004, 'Patient satisfaction with triage nursing in a rural hospital emergency department', Journal of Nursing Care Quality 19(3), 263-268.

American College of Surgeons Committee on Trauma, 1997, Advanced trauma life support for doctors, 6th edn., Chicago, American College of Surgeons.

Augustyn, J.E., 2006, 'An investigation into the implementation of an emergency unit triage system in a selected private hospital', MA Cur dissertation, University of Pretoria.

Bekerman, L., Hay, E., Peled, R. \& Rosenberg, G., 2001, 'Quality assurance of nurse triage: Consistency of results over three years', American Journal of Emergency Medicine 19(2), 113-117.

Bracken, J., 2003, Triage in SHEEY'S Emergency nursing: Principles and practice, 5th edn., St Louis, CV Mosby. 
Bucknall, T. \& Gerdtz, M., 2000, 'Australian triage nurses' decision-making and scope of practice', Australian Journal of Nursing 18(1), 24-33.

Burns, N. \& Grove, S.K., 2001, The practice of nursing research: Conduct, critique $\mathcal{E}$ utilization, 4th edn., Philadelphia, WB Saunders.

Caroline, N.L., 1995, Emergency care in the streets, 5th edn., Philadelphia, Lippincott, Williams \& Wilkins.

De Vries, S., Gottschalk, S.B., Wallis, L.A. \& Wood, D., 2005, 'The Cape Triage Score', Nursing Update 29(7), 38-43.

Edwards, B., 1999, 'What's wrong with triage?', Emergency Nurse 7(4), 19-23.

Gottschalk, S., 2004, 'Triage - a South African perspective', Continuing Medical Education 22(6), 325-327.

Heyns, T., 2003, 'Core competencies of the emergency unit nurse in life-threatening situations in the emergency care environment in South Africa', Masters dissertation, University of Pretoria.

Jones, C., 1993, Triage decisions: 'How are they made?', Emergency Nurse 1(1), 13-14.

LoBiondo-Wood, G. \& Harber, J., 1998, Nursing research: Methods, critical appraisal, and utilization, St Louis, CV Mosby.

Lohr, K.N. 1990. Medicare: A strategy for quality assurance, Washington DC, National Academy Press.

Mallet, J. \& Woolwich, C., 1990, 'Triage in accident and emergency departments', Journal of Advanced Nursing 15(1), 1443-1451.
Nicol, A. \& Steyn, E., 2004, Handbook of trauma for Southern Africa, Cape Town, Oxford University Press.

Nielson, D., 2004, 'Improving emergency department patient satisfaction when triage nurses routinely communicate with patients as to reasons for waits: One rural hospital's experience', Journal of Emergency Nursing 30(4), 336-338.

Parish, C., 2000, 'Nurse-led triage will help streamline emergency unit services', Nursing Standard 14(39), 6.

Pillay, V., 2005, 'Thrombolythic therapy in acute myocardial infarction - the specific barriers related to "time" delays in the door to needle time at the Al Ain Hospital', MA Cur dissertation, University of South Africa.

Polit, D., Beck, C. \& Hungler, B., 2001, Essentials of nursing research: Methods, appraisal and utilization, Philadelphia, JB Lippincott.

Saks, M. \& Allsop, J., 2007, Researching health: Qualitative, quantitative and mixed modes, London, Sage.

South Africa (Republic). Department of Health 2003: National Health Bill. (Bill no 32B of 2003), Pretoria, Government Printers.

Swansberg, R.C., 1993, Introductory management and leadership for clinical nurses, London, Jones \& Bartlett.

Woolwich, C. 2000. Accident and emergency: Theory into practice, London, Balliliére Tindall.

World Health Organization 2003, Guidelines for essential trauma care, Geneva, Injuries and Violence Prevention Department, International Association for Trauma and Surgical Intensive Care. 